\title{
Interactive comment on "The DeepMIP contribution to PMIP4: methodologies for selection, compilation and analysis of latest Paleocene and early Eocene climate proxy data, incorporating version 0.1 of the DeepMIP database" by Christopher J. Hollis et al.
}

Christopher J. Hollis et al.

c.hollis@gns.cri.nz

Received and published: 15 June 2019

We appreciate the positive comments from the reviewer and have addressed the typos and inconsistencies identified by all three reviewers and co-authors. Our responses to other comments are provided below [in square brackets]

Specific Comments: C3 land plant carbon isotope proxy for atmospheric CO2 I' am unfamiliar with this proxy and therefore sought additional information about this approach. 
In doing so I came across a recent paper that argues that the model presented in this work (Schubert and Jahren, 2012) fails independent validation tests (see below). The authors discuss validation against ice core data in this section, which given that this is much lower CO2 than for the Paleocene / Eocene, seems insufficient. In addition, the positive and negative errors stated in this section (120\% and $40 \%$ seemed large). Could the authors comment on the findings of the Lomax et al., (2019) paper, which indicate that this proxy is poorly constrained, when growth conditions / water use efficiency is not well understood. Could the authors either update the paper with clear caveats or this section be removed from the paper? Lomax et al., (2019) carry out validation experiments for this proxy and their results indicate that... 'the model fails to accurately predict $\mathrm{CO} 2$ with substantial under prediction in $\mathrm{CO} 2$ in experiments that were designed to simulate Cenozoic and Mesozoic atmospheric environments. Our findings suggest serious limitations in the proposed proxy as delivered estimates of $\mathrm{CO} 2$ are neither precise nor accurate when compared to known growth conditions.'

[Lomax et al. (2019) demonstrated experimentally that plants grown under water stress showed the same relative change in $\triangle 13 \mathrm{C}$ value with increasing $\mathrm{CO} 2$ concentration as observed in well-watered experiments (e.g., Schubert and Jahren, 2012), but with lower $\triangle 13 \mathrm{C}$ values overall. Their experimental data are consistent with modelled results for the predicted effect of water stress on $\Delta 13 \mathrm{C}$ value across multiple levels of $\mathrm{CO} 2$ (see Fig. 4a within Schubert and Jahren, 2018). We now note, however, that the approach used by Lomax et al. (2019), and also by Barral et al. (2017) for the Cretaceous, cannot be used to accurately predict $\mathrm{CO} 2$. We include these caveats and the following new text in section 6.5.4 Recommended methodology of C3 land plant proxy:

"However, Lomax et al. (2019) demonstrated experimentally that plants grown under water stress showed the same relative change in $\Delta 13 \mathrm{C}$ value with increasing $\mathrm{CO} 2$ concentration as observed in well-watered experiments (e.g., Schubert and Jahren, 2012 ), but with lower $\Delta 13 \mathrm{C}$ values overall. Their experimental data are consistent with results that modelled the predicted effect of water stress on $\Delta 13 \mathrm{C}$ value across

Printer-friendly version

Discussion paper
Interactive comment 
multiple levels of CO2 (see Fig. 4a within Schubert and Jahren, 2018). Nevertheless, both chamber (Lomax et al., 2019) and deep-time (Barral et al., 2017) studies have tried to use Eq. (26) to quantify $\mathrm{CO} 2$ and failed to account for the effects of growing conditions and plant species type on $\Delta 13 \mathrm{C}$ value. Such attempts highlight the need to use Eq. (27) with robust estimates of $\Delta(\Delta 13 C)$ (after Schubert and Jahren, 2015) in order to accurately quantify CO2." (Equation numbers refer to revised text.)]

Interactive

General typos: Partly based on the lack of clarity with the C3 land plant carbon isotope proxy for atmospheric $\mathrm{CO} 2$ described above, would the authors consider adding a summary table that could list all the proxy methods and a few columns that briefly convey, for example, their maturity (i.e. new in progress, established, well used understood), a measure of confidence in the method and perhaps whether there is a consistent bias, in order to convey some of this important information to the reader as an overview?

[We agree that a summary table of the proxies covered in the paper would be helpful to readers, and so propose to include one in the final version. However, it's difficult to include all the aspects mentioned above in a table. Even the most mature proxy, oxygen isotopes, has a wide range of sources of error and bias, which are best addressed in the text. Instead we add a column to the table to indicate how many of the proxy records included in the data compilation are considered to be reliable.]

P5, L6 expand CIE here and use abbreviation from here on [Corrected] P9, L17 bias in [Corrected] P26, L24 proxy [Corrected] P33, L11 âŮęC [Corrected] P33, L24 combining [Corrected] P42,' L31 from a single typically? Unclear sentence [Corrected] $\mathrm{P} 45, \mathrm{~L} 17^{\prime}$...such that it becomes an updated, comprehensive tool ... (possible change of text) [Revised] P46, L10 Southern Ocean [Corrected] References Lomax, B. H., C. A. Knight, and J. A. Lake. "An experimental evaluation of the use of C3 $\delta 13 \mathrm{C}$ plant tissue as a proxy for the paleoatmospheric $\delta 13 \mathrm{CO} 2$ signature of air." Geochemistry, Geophysics, Geosystems 13.9 (2012).

Printer-friendly version

Discussion paper

Please also note the supplement to this comment: 
https://www.geosci-model-dev-discuss.net/gmd-2018-309/gmd-2018-309-AC3supplement.pdf

Interactive comment on Geosci. Model Dev. Discuss., https://doi.org/10.5194/gmd-2018-309, 2019. 